\title{
First-Line Protective Service Worker Supervisors and Managers
}

National Cancer Institute

\section{Source}

National Cancer Institute. First-Line Protective Service Worker Supervisors and

Managers. NCl Thesaurus. Code C122455.

Workers who directly supervise and coordinate the activities of protective service workers. 